\title{
ROMANIA SI BASARABIA-O SUTA DE ANI DE FRAMANTARI
}

\author{
Prof. Dr. Nicholas Dima, USA.
}

Basarabia si Bucovina raman marea problema etnico-teitoriala nerezolvata a Romaniei. Reunirea cu tara a pamantului stramosesc dintre Prut si Nistru ne preocupa pe multi dintre noi, dar ar trebui sa-i preocupe si pe liderii tarii. Reintregirea reprezinta o prioritate nationala. La nivel personal, intelectualii constienti afirma si reafirma prin cercetari, conferinte si luari de pozitii, ceace nu poate fi nici uitat si nici abandonat. Daca azi renuntam la ideia reunficarii, maine, Romanii Basarabeni si Bucovineni vor impartasi soarta Macedo-Romanilor de la sud de Dunare. Ori chiar mai rau; in numele unui internationalism fals, ne putem trezi $\mathrm{cu}$ o entitate statala straina in mijlocul tarii.

Istoria tritoriului de peste Prut este de acuma bine cunoscuta. Ea a fost rezumata clar si concis in rezolutia Senatului American Nr. 148 din 11 iunie 1991. Voi reveni asupra acestei importante rezolutii pentru ca ea trebuia sa dea de gandit conducerii post-ceausiste si in egala masura conducerii de azi a tarii...

De-a lungul ultimilor 200 de ani Rusia si fosta Uniune Sovietica au incalcat de repetate ori si in mod brutal teritoriul tarii si au cauzat avarii si suferinte de neimaginat. In urma cu 100 de ani, Basarabia si Bucovina s-au reunit cu tara, dar Moscova ne-au invadat si sfartecat din nou in 1940 si 1944. Au urmat sute de mii de arestari, deportari si executii sumare pe care le-am mentionat in ultima mea carte intitulata Marturii dedicate Eroilor si Martirilor nostri. Informatiile pentru capitolul Basarabia, Bucovina si Siberia leam cules din diferite carti publicate in tara dupa 1989, dar si din unele documente aparute anterior in occident.

Intre sursele consultate in America si citate in cartea Bessarabia and Bukovina, publicata in 1982, am citat si cartea Basarabia Dezrobita care a aparut in tara in timpul razboiului. Acea carte $\mathrm{m}$-a cutremurat prin fotografiile ei. In acelasi timp $\mathrm{m}-\mathrm{a}$ indispus deoarece cartea, pe care am gasit-o in biblioteca Departamentului de Stat dupa aproape patru decenii de la publicarea ei, avea foile netaiate. (Pentru cei care nu stiu, in trecut multe carti erau disitribuite cu foile de hartie unite intre ele. Primul cititor le despartea atent cu un cutit). Nimeni de la Departamentul de Stat nu catadicsise sa o deschida! Cu asemenea 'specialisti' s-a decis soarta Basarabiei dupa razboi. Si pentru ca am ajuns aici, precizez ca atitudinea ambigua a Americii rezulta din faptul ca senatul nu a ratificat nici odata reunirea Basarabiei cu tara. Motivele amanarii ratificarii s-au datorat luptelor de culise si intereselor triviale dintre partide.

Redau in continuare cateva fragmente ale unor recenzii si comentarii incluse in cartea Marturii, si sper sa-i readuc la realitate pe unii romani care si-au uitat trecutul si confratii de peste Prut. Incep cu cartea In Gura Foametei scrisa de Alexei Vakulovski. Autorul ne ofera o serie de marturii ale supravietuitorilor din satul Antonesti. Acei suspravietuitori, acele fiinte umane, erau in varsta de 6 pana la 14 ani in timpul foametei din 1946-1947. Trebue precizat de la inceput insa un lucru important pentru ca nu reiese din lectura marturiilor. Taranii ramasi la sate in Basarabia in 1944 erau cu precadere oameni saraci si cu putina stiinta de carte. Intelectualii, oamenii instariti, cei cu sentimente romanesti bine cunoscute, fusesera deja arestati, impuscati, ori deportati inca din 1940. Iata un fragment marturisit de Vasile Gaidau la batranete si care la vremea foametei avea opt ani:

...Foametea a fost foarte bine pusa la cale...acum imi dau seama de asta... a fost organizata. Au vrut stalinistii sa ne mature de pe fata pamantului. Eu atunci, in plina foamete, am ramas fara tata la sase ani, iar la sapte ani si jumatate am ramas si fara mama... Se ducea fratele Mihai, nascut in 1932, la balta, spargea gheata, aduna scoici, papura, le prefaceam in turte si le mancam. Eram patru frati... Cum se vede, s-a gandit 
cineva ca razboiul $i$-a ucis pe putini dintr-ai nostri si s-au gandit animalele sa nascoceasca alt razboi, cel al foametei... A murit sora lui tata, a murit cumnatul lui tata, a murit matusa Olimpia, a murit matusa Irina... Au murit multi. Era mare foamete... (p. 215).

Alta marturie ne-o ofera Cosma Munteanu, si el copil la vremea respectiva:... La noi in sat oamenii, ca sa nu moara de foame, au mancat si coaje de copac, si iarba, si miez de rasarita, si papura, si caini, si matze, si cioroi, si scoici, si sobolani, dar multumim, nici un caz nu a fost sa-si manance poprii copii...La Purcari insa, ca sa se salveze, doua femei au hotarit sa-si manance copiii. Au mancat un copil iar cand urma sa$l$ taie pe al doilea, mama lui n-a vrut sa-l ucida... Femeia aceia care si-a mancat propriul ei copil a fost pedepsita si s-a intors din lagar cu o fata luata de suflet. (p.140).

Sute de mii de Basarabeni si Bucovineni au fos deportati in Siberia in conditii de cosmar si multi dintre ei nu s-au mai intors nici odata. Parintele Vasile Tepordei originar din Chisinau a fost ocrotit de mana lui Dumnezeu. El a fost arestat in tara unde se refugiase, a fost condamnat de KGB la 25 de ani deportare, si s-a intors acasa in 1956 dupa sapte ani si 157 de zile in Siberia. Cartea sa Amintiri din Gulag descrie tragedia prin care a trecut... Viata in Gulag a fost mai grea si mai brutala decat in iad. Sute de mii de oameni au murit si au fost aruncati in gropi comune, scrie autorul. Parintele Tepordei marturiseste ca fiind grav bolnav a fost salvat de un medic al lagarului in care se afla... Doctorita crescuse intr-un orfelinat dupa ce parintii ei fusesera arestati si deportati. De peste 20 de ani ea nu mai stia nimic de soarta lor. In amintirea tatalui, preot Ortodox ca si parintele Tepordei, doctorita a vrut sa salveze un preot...

Alte experiente Siberiene au fost insa inexprimabil de zguduitoare. Iata ce isi aminteste despre Siberia Tamara Oala-Plesca in cartea $\mathrm{Sa}$ nu ne razbunati; marturii culese si publicate de monahul Moise... Sunt din satul Sofia de langa Drochia, din Basarabia. M-am nascut in anul 1935, in luna iulie. Eram trei baieti si trei fete... Familia noastra a fost deportata in noaptea de 12 spre 13 iunie 1940.... Imi aduc aminte ca noua, la toti, ne dadea o painica de secara, sambata. Pentru toti cati eram acolo, cate suflete eram, aveam painea asta. Pentru sase suflete, o paine pe saptamana! In rest, era loboda si urzica...

...Noi noaptea aceia nu am inchis ochii... $E i$, cand am ajuns dimineata, bunica nu mai era... Era teapana. Acuma, cum s-o ingroape? Unde? Se duce fratele sa-i sape groapa. El era umflat mai tare decat noi... A sapat acolo, poate jamate de metru, dar era ghiata si a tasnit niste apa si a pus-o acolo pe bunica, in apa... Dupa ce a murit bunica s-a dus si fratele mai mic. Tot spunea: papa, papa, papa... Ce sa-i dea mama... cand $n$ aveam nimic? Si a zis fratele 'papa, papa...' pana a murit. A murit cerand de mancare. Lam gasit teapan si pe dansul. L-a dus si l-a pus langa bunica...

...Cand fratele Vasile s-a umflat foarte tare, a murit si el. Acuma nu mai avea cine sa ne aduca nici painea aceia pe care ne-o aducea el... Acuma, daca a murit fratele, cine sa-l duca la groapa? Pan'la urma or venit niste oameni, moldoveni de-ai nostri care lucrau si ei acolo, si l-au asezat pe un tol si lau scos din casa... Si ne-am culcat flamande. Ce aveam sa facem? Am mancat numai niste burueni, acolo, pe care le-am mancat asa, crude, ca mama nici nu mai putea sa le fiarba. Am mancat amandoua si ne-am culcat. Cand m-am trezit dimineata... sora umflata, moarta. Au mai venit oamenii, au luat-o si pe sora si au dus-o alaturi de ceilalti. Si acuma erau patru cruci acolo...

Unii deportati s-au intors si cu chiu cu vai si-au refacut viata. Sistemul Sovietic a continuat sa sape insa la radacina romanilor Basarabeni si pe unii i-a stramutat in Kazakhstan. Cei mai multi din cei ramasi au supravietuit cu gandul la Romania si nutrind reunirea cu patria. Pe unii din liderii lor i-am intalnit la Chisinau in octombrie 1989 cand am fost trimis ca reporter in Basarabia. Am cunoscut atunci o generatie de aur: scriitori, poeti, artisti, actori, carturari, care au redesteptat spiritul national si care au asteptat sa li se intinda o mana frateasca din tara. $\mathrm{Nu}$ li s-a intins nici odata! (In cartea sus amintita de marturii am redat detaliat acea vizita si intalnirile cu Romanii din Basarabia si Bucovina). Evenimentele din decembrie1989 au dus la o mare schimbare in Romania, dar 
schimbarea a fost in primul rand intre nomeclaturistii de la varf si in favoarea lor. In 1990 am fost trimis din nou de Vocea Americii in misiune de reporter in tara. A fost prima mea revenire in tara dupa un exil de 22 de ani. $\mathrm{Cu}$ acel prilej am intalnit multi noi conducatori ai noului regim iar la palatal Cotroceni i-am luat un interviu presedintelui Ion Iliescu. In acel interviu l-am intrebat daca ar putea discuta personal cu fostul lui coleg de universitate Mikhail Gorbachev problema retrocedarii Basarabiei. Raspunsul sau a fost vag. Nu banuiam la acea ora ca Iliescu facuse deja un targ cu Moscova. Basarabia a fost pretul pentru care a obtinut de la KGB presedintia Romaniei. In anii care au urmat, noua conducucere a tarii a uitat de Basarabia. America si-a amintit insa de ea, dar Bucurestiul a ignorant si a ascuns un episod care putea sa schimbe cursul istoriei.

La data de 28 iunie 1991 Senatul American a luat in discutie optiunile Basarabiei si Bucovinei si le-a rezumat succint, dar suficient de detaliat, in rezolutia Nr. 148. Redau in incheierea acestei prezentari paragrafele de inceput si de sfarsit ale rezolutiei. Cine doreste o poate citi in intregime atat in limba engleza cat si in limba romana. Ramane ca fiecare dintre noi sa o contempleze, iar autoritatile sa actioneze si sa incerce sa realizeze acum ceace nu au facut imediat dupa revolutie. Traducerea a fost publicata intr-un ziar din tara...

Pentru exprimarea convingerii Senatului că Statele Unite trebuie să sustină dreptul la autodeterminare al poporului din Republica Moldova şi Bucovina de Nord...

...Aşadar, să fie decis, în momentul de faţă, că este convingerea Senatului că Guvernul Statelor Unite trebuie

1) Să susţină dreptul la autodeterminare al poporului Moldovei şi al Bucovinei de Nord, ocupate de Uniunea Sovietică, şi să emită o declarație cu acest scop; şi

2) Să susţină eforturile viitoare ale Guvernului Moldovei să negocieze în mod paşnic, dacă aceasta le este voia, reunificarea României cu Moldova şi cu Bucovina de Nord, după cum s-a stabilit în Tratatul de Pace de la Paris din 1920, în normele predominante ale dreptului internaţional şi în conformitate cu Principiul 1 al Actului Final de la Helsinki. 'Nicholas Dima, USA, 3 martie 2018..

PS: Commitetul Romano-American pentru Basarabia a facut numeroase demersuri in favoarea reunirii Basaraiei cu tara.

O declaratie cu textul de mai jos a fost citita in Parlamentul Romaniei de deputatul Eugen Tomac.

Stimati compatrioti de la Nistru pan'la Tisa... si de peste hotare:

Comitetul Romano-American pentru Basarabia a fost infiintat in anul 2000 de un grup de Romani din Statele Unite cu scopul promovarii unirii Basarabiei cu tara.

Nici o forta din lume, Rusia si Uniunea Sovietica in trecut, Uniunea Europeana si tendinta Globalista de azi, nu poate impiedica reunficarea tarii!

Romanii integri si cinstiti au datoria sa lupte pentru idealul unirii! Ne indeamna fratii din mormintele fara cruci uitate prin Siberii si Kazahstane! Daca renuntam la Basarabia, Rusia va incerca sa ajunga pana la Carpati.

Si daca noi nu ne revendicam drepturile acum in ceasul al 12-lea maine altii vor incerca sa ne dezmembreze tara. Dodonii si Putinii umbla deja cu harti trunchiate si cu amenintari.

Sa stam neclintiti si sa avem curajul sa sustinem adevarul. Basarabia e pamant romanesc si punctum! Chiar si dusmanii te respecta atunci cand iti sustii cauza cu demnitate.

Cerem Presedintiei, Guvernului si Parlamentulului Romaniei sa ia atitudine ferma. Recentele alegeri din Basarabia au dovedit odata in plus cat de manipulata este aceasta provincie-martir si cat de terfelite au ajuns cozile de topor de la Chisinau.

Un vechi proverb sustine ca atunci cand oamenii si-au pierdut onoarea si deminitatea, ridica-te tu si stai drept ca o lumanare.

A sosit timpul sa luam atitudine!

Frati Romani din tara si din Basarabia, suntem alaturi de voi! Impreuna vom in vinge!

Comitetul Romano-American pentru Basarabia, 27 Martie 2017 